\title{
PENGUKURAN TINGKAT KAPABILITAS SISTEM TATA KELOLA TI MENGGUNAKAN COBIT 5 DENGAN ISO 38500
}

\author{
Muhammad Basyier Ardima1, Rahmat Gernowo², Vincencius Gunawan Slamet ${ }^{3}$ \\ ${ }^{1}$ Magister Sistem Informasi, Sekolah Pascasarjana, Universitas Diponegoro \\ ${ }^{2,3}$ Dapartemen Fisika, Fakultas Sains dan Teknologi, Universitas Diponegoro \\ Email: ${ }^{1}$ basyierardima@gmail.com, ${ }^{2}$ gernowo@yahoo.com, ${ }^{3}$ geonangie@fisika.undip.ac.id
}

(Naskah masuk: 09 Januari 2020, diterima untuk diterbitkan: 27 April 2020)

\begin{abstract}
Abstrak
Penggunaan sistem informasi dan teknologi informasi pada suatu organisasi sangat dibutuhkan karena sistem informasi sangat berpengaruh dalam menunjang kinerja suatu organisasi. Tata kelola sistem informasi sangat dibutuhkan untuk mencapai penyelenggaraan institusi yang lebih efisien dan efektif. Unit Pelaksanaan Teknis Teknologi Informasi dan Komunikasi (UPT TIK) Universitas Negeri Semarang (Unnes) memiliki beberapa bagian divisi yaitu divisi data, sistem informasi dan layanan, dan infrastruktur. Penelitian ini menggunakan COBIT 5 dengan ISO 38500 untuk pengukuran sistem informasi tata kelola TI pada UPT TIK. Tujuan penelitian ini untuk mengukur tingkat kapabilitas tata kelola TI sehingga dapat dijadikan acuan dalam memperbaiki sistem tata kelola TI. Data penelitian diperoleh dari UPT TIK berupa visi misi institusi dengan dokumen pendukung antara lain dokumen rencana kerja dan kuisioner. Dari hasil penelitian pengukuran menggunakan COBIT 5 dengan ISO 38500 diperoleh 17 Domain COBIT 5 dengan tingkat kapabilitas 2. Hal ini berarti pada tingkat managed process, institusi telah melakukan perencanaan, pengontrolan dan penyesuaian terhadap proses TI yang sedang berlangsung. Penelitian ini menghasilkan nilai GAP sebesar 1 yang diperoleh dari selisih antara target yaitu 3 dengan tingkat kapabilitas sebesar 2. Dengan ini dapat dikatakan bahwa kombinasi COBIT 5 dan ISO 38500 dapat dijadikan acuan dalam memperbaiki sistem tata kelola TI.
\end{abstract}

Kata kunci : COBIT 5, ISO 38500, tata kelola TI

\section{CAPABILITY LEVEL MEASUREMENT OF IT GOVERNANCE SYSTEM USING COBIT 5 WITH ISO 38500}

\begin{abstract}
The usage of information systems and information technology in an organization is essential since information system is very important in supporting the performance of an organization. Information system governance is required to attain more efficient and effective performance of institutions. The technical implementation unit of information technology and communication (UPT TIK) State University of Semarang (Unnes) having several divisions that is the data division, information systems and services, and the infrastructure. This study applied COBIT 5 with ISO 38500 to measurement information system of IT governance of UPT TIK. The purpose of this research is to measure the capabilities of IT governance so it can be used as reference in improving the information system management. The research data is obtained from UPT TIK in form of the vision and mission of institution with the supporting documents such as the document of work plan and questionnaires. The measurement research using COBIT 5 with ISO 38500 obtained 17domains COBIT 5 with a capability level of 2. This means on the managed process level, institution have done planning, control and adjustments to the Information Technology on-going process. This research gained a GAP value of 1 from the margin between the targets of 3 with a capability level of 2. Therefore, it can be described that the combination of COBIT 5 and ISO 38500 can be used as a reference in improving IT governance systems.
\end{abstract}

Keywords : COBIT 5, ISO 38500, IT Governance

\section{PENDAHULUAN}

Sistem informasi dan teknologi informasi menjadi kunci dalam pengelolaan organisasi karena sistem informasi sangat menunjang setiap bidang dan komponen dalam suatu organisasi karena dapat mewujudkan tata kelola yang baik dalam mencapai visi misi organisasi (Juiz, Guerrero, \& Lera, 2014). Era globalisasi, peran tata kelola dalam sebuah 
institusi yaitu supaya terciptanya proses penyebaran ilmu dalam kegiatan belajar mengajar yang efektif, operasional kegiatan institusi lebih transparan, transparansi kinerja berbasis evaluasi bisa meningkat (Fransiskus Adikara, 2013).

Unit pelaksanaan kerja teknologi informasi dan komunikasi (UPTTIK) Universitas Negeri Semarang (UNNES) memiliki 3 bagian yaitu devisi sistem informasi dan layanan, devisi infrastruktur dan devisi data. Pemanfaatan teknologi pada UPT TIK membutuhkan pengelolaan yang tepat sumber daya yang berkualitas serta anggaran yang tidak sedikit dengan risiko kegagalan yang tinggi yaitu bila terjadi gangguan pada TI yang dimiliki sehingga dibutuhkan suatu tata kelola yang tepat dalam memaksimalkan pemanfaatannya.

COBIT menjadi kerangka kerja yang banyak digunakan dalam penilaian terhadap tata kelola teknologi informasi. Hal ini terlihat dari pencapaian COBIT dalam mendapatkan pengakuan dari seluruh dunia merupakan framework terpercaya dalam bidang tata kelola TI (ISACA, 2013) sedangkan ISO 38500 merupakan standar internasional yang dibuat untuk mengarahkan tata kelola teknologi informasi pada sebuah organisasi (Grembergen, 2004).

Pada penelitian sebelumnya COBIT 5 pernah diterapkan pada perusahaan keuangan dengan tingkat kapabilitas 1 (Rooswati \& Legowo, 2018). Penerapan COBIT 4.1 pada pendistribusian kelas di Universitas Internasional Semen Indonesia memperoleh tingkat kapabilitas 1 (Muthoharoh, Dwipa, \& Dewi, 2019). Implementasi COBIT 5 untuk tata kelola TI rumah sakit merupakan faktor penentu dalam mengoptimalkan visi dan misi instansi tersebut (Nugroho, 2017). Penerapan COBIT 5 pada perusahaan otomotif diperoleh tingkat kapabilitas 1 (Hareva \& Legowo, 2017) sedangkan ISO 38500 pernah diterapkan untuk penilaian tata kelola TI pada Universitas Indonesia yang menyatakan bahwa model penilaian ini dapat meningkatkan tingkat kapabilitas pada tata kelola TI (Putri \& Surendro, 2016). Penelitian lain dari ISO 38500 diimplementasikan untuk keamanan tata kelola TI yang menyatakan bahwa ISO 38500 dapat meningkatkan tata kelola pada organisasi (Ahuja \& Chan, 2015).

Berdasarkan penelitian sebelumnya, maka penelitian ini mengkombinasikan COBIT 5 dengan ISO 38500 pada UPT TIK UNNES yang bersumber dari visi misi pada institusi. Proses teknologi informasi pada COBIT 5 mendukung prinsip-prinsip dan pendekatan implementasi terhadap ISO 38500 (ISACA, 2013), maka kerangka kerja yang fokus digunakan untuk mengukur tingkat kapabilitas adalah COBIT 5 dan ISO 38500. Tujuan penelitian ini untuk mengukur tingkat kapabilitas tata kelola TI sehingga dapat dijadikan acuan dalam memperbaiki sistem tata kelola TI. Berdasarkan prinsip ISO 38500 menggunakan proses COBIT 5 maka menghasilkan model evaluasi untuk mengukut tingkat kematangan pelaksanaan tata kelola teknologi informasi di UPT TIK. Serta menentukan target dan menilai keadaan saat ini maka didapat gap.

\section{METODE PENELITIAN}

\subsection{Tata Kelola TI}

Tata kelola TI merupakan struktur hubungan, proses dan tata cara yang digunakan untuk mengarahkan, mengendalikan dan mengembangkan strategi serta sumber daya sehingga bisa mencapai apa yang diharapkan (Andry, 2016). Tata kelola TI merupakan hubungan dan proses untuk mengontrol serta mengarahkan institusi supaya tujuan bisnis dapat mencapai melalui penambahan nilai yang terkait dengan pengelolaan proses TI (Sarno, 2009). Standar kerangka kerja international ISO/IEC 38500 juga digunakan untuk kesesuaian bisnis dan teknologi informasi melalui persetujuan portofolio proyek. Hal tersebut merupakan salah datu mekanisme untuk menerapkan tata kelola IT yang sesuai standard (Juiz dkk, 2012). Tata kelola teknologi informasi merupakan. Banyak kerangka kerja dalam tata kelola TI antara lain COBIT, TOGAF, ITIL dan ISO (Maskur, Adolong, \& Mokodongan, 2018), COBIT merupakan framework yang paling bagus di antara TOGAF, ITIL, ISO karena pada framework COBIT sudah mencakup standar - standar framework lainnya (Isaca, 2016).

\subsection{COBIT 5}

COBIT 5 memiliki 2 pendekatan baru yaitu pendekatan proses capability model untuk mengelola risiko dan perbaikan model (Pasquini, 2013). COBIT 5 melakukan perluasan dan pengembangan dari COBIT 4.1 dengan cara menselaraskan kerangka besar lainnya, sumber daya dan standar, termasuk ISACA Val IT dan risiko TI, Technology Infrastructure Library (ITIL) dan standar yang terkait dari International Organization for Standarization (ISO) (ISACA, 2012) . Adapun kerangka kerja COBIT 5 yaitu model tata kelola TI yang terdiri dari rangkaian proses TI terbaik, yang bisa diaplikasikan pada perusahaan supaya tata kelola dan manajemen TI bisa lebih baik dengan cara mengelola bernacam macam kebutuhan manajemen, kesenjangan risiko bisnis, kebutuhan dan masalah teknis TI. COBIT 5 memiliki 5 domain antara lain (ISACA, 2013) :

1) Evaluate, Direct and Monitor (EDM)

Proses pengelolaan ini berkaitan dengan penilaian tata kelola pemangku kepentingan, sumber daya dan optimasi risiko, meliputi praktik dan kegiatan yang memiliki tujuan memilih pilahan yang strategis dengan cara mengevaluasi.

2) Align, Plan and Organize (APO)

Pada proses ini terdiri dari strategi, teknik serta mengidentifikasi sampai mana TI ikut serta dalam kepentingan institusi.

3) Build, Acquire and Implementation (BAI) 
Proses ini memiliki beberapa solusi untuk menerapkan strategi yang telah dibentuk.

4) Deliver, Service and Support (DSS)

Pada proses ini semua solusi TI telah dijalankan dan bisa melayani serta mendorong pengguna sesuai yang diharapkan.
5) Monitor, Evaluate and Assess (MEA)

Dalam proses ini sudah sama dengan yang direncanakan dan melaksanakan evaluasi proses yang belum optimal.

Dari domain COBIT 5 tersebut memiliki 37 proses bisa dilihat dalam Gambar 1.

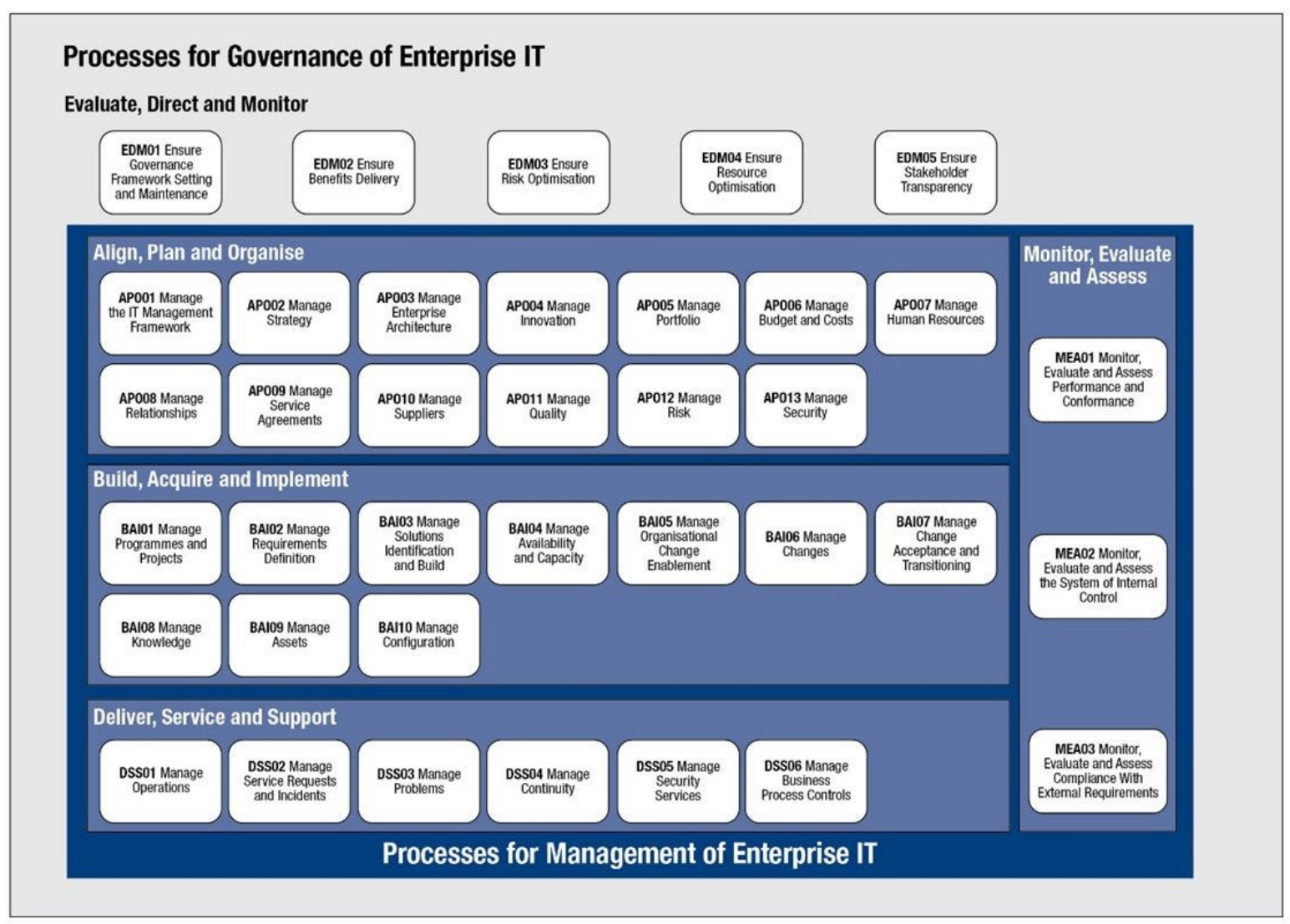

Gambar 1. COBIT 5 (ISACA, 2013)

Berikut ini merupakan tingkat kapabilitas proses (ISACA, 2013)) :

1) Incomplete Process (Level 0)

Pada level ini tidak sedikit bukti atau tidak ada bukti sistematik dari tujuan proses. Maka proses dikatakan gagal atau tidak dijalankan sesuai tujuan.

2) Performed Process (Level 1)

Pada proses ini menentukan suatu proses diaplikasikan bisa sampai tujuan.

3) Managed Process (Level 2)

Work products-nya terkelola, dimonitoring dan diimplementasikan sesuai dengan tujuan. Pada proses ini dikelola yang terdiri dari rencana, kontrol dan kesesuaian.

4) Established Process (Level 3)

Pada proses ini supaya bisa mendapatkan hasil yang diinginkan maka proses yang dibangun selanjutkan di jalankan sesuai dengan proses yang telah didefinisikan.
5) Predictable Process (Level 4)

Pada level 4 untuk mencapai outcome yang diinginkan proses yang dibangun selanjutnya dijalankan sesuai aturan yang ditentukan.

6) Optimising Process (Level 5)

Terpenuhinya tujuan bisnis sekarang dengan yang akan datang maka proses yang terprediksi akan terus diperbaiki.

\subsection{ISO 38500}

ISO 38500 merupakan standar tata kelola TI yang dapat dievaluasi, dikendalikan dan diarahkan penggunaannya supaya bisa mengawasi dan mendorong penggunaan TI sesuai dengan rencana, termasuk kebijakan dan strategi (Putri \& Surendro, 2016). Model tata kelola bisa dilihat dalam Gambar 2. 


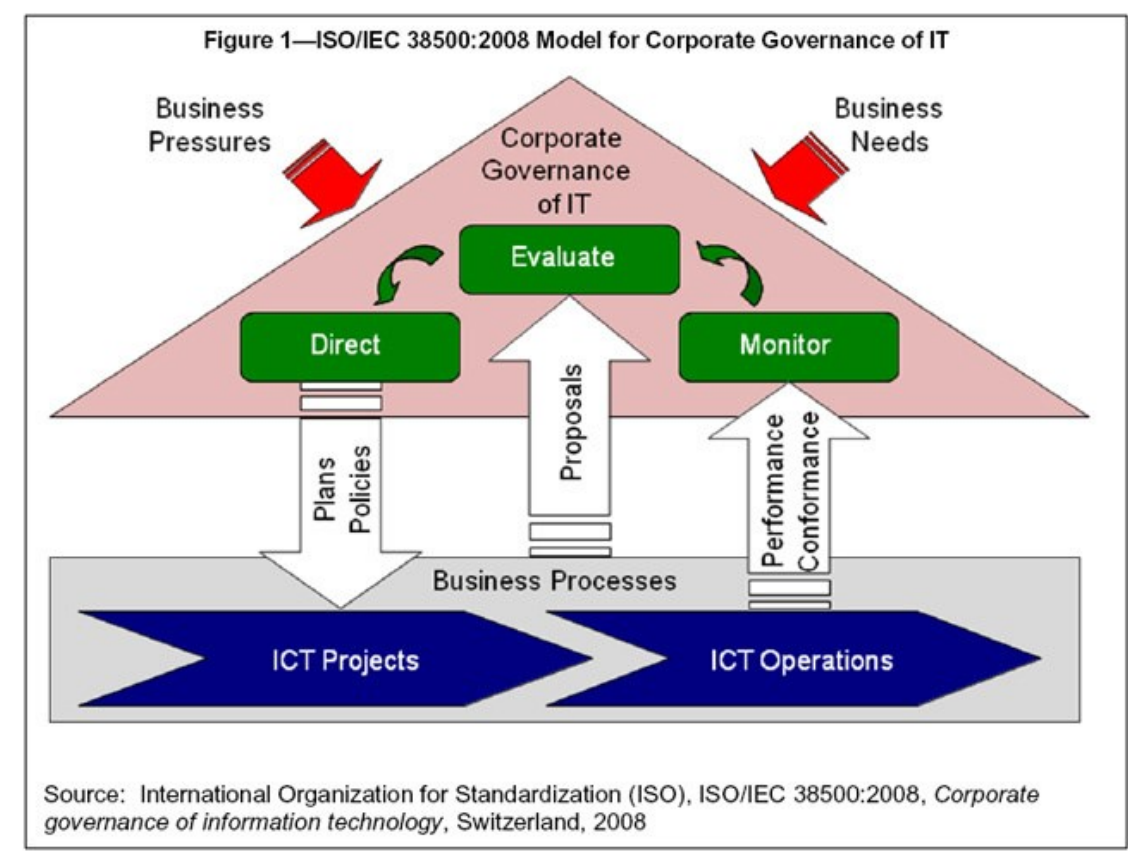

Gambar 2. Model Tata Kelola Teknologi Informasi (Putri \& Surendro, 2016)

ISO 38500 mempunyai beberapa prinsip untuk penggunaan TI yang efektif, efisien dan dapat diterima. Prinsip - prinsip ISO 38500 sebagai berikut (Putri \& Surendro, 2016, Grembergen dkk., 2009) :

1) Tanggung Jawab

Memasok dan permintaan Teknologi Informasi merupakan tanggung jawab yang harus difahami dan diterima pada setiap individu ataupun kelompok dalam sebuah perusahaan.

2) Strategi

Kemampuan TI saat ini dan masa mendatang akan diperhatikan untuk menyesuaikan strategi bisnis perusahaan.

3) Akuisisi

Pembuatan keputusan yang jelas dan transparan maka membutuhkan analisis yang sesuai dan berkelanjutan sehingga bisa mendapatkan bukti yang valid.

4) Kinerja

Teknologi informasi bersamaan tujuan untuk mendorong perusahaan mempunyai, penyedia layanan, kualitas layanan serta level/ tingkat layanan untuk persiapan di masa mendatang.

5) Kesesuaian

Teknologi Informasi sesuai dengan peraturan wajib dan undang - undang.

6) Perilaku Manusia

Pada saat ini ataupun masa yang akan datang bisa memenuhi kebutuhan semua orang dengan cara melaksanakan praktik, keputusan dan kebijakan TI memperlihatkan perilaku dengan rasa hormat.

\subsection{Alur Penelitian}

Tahapan penelitian Evaluasi tata kelola TI, ditunjukkan Gambar 3.

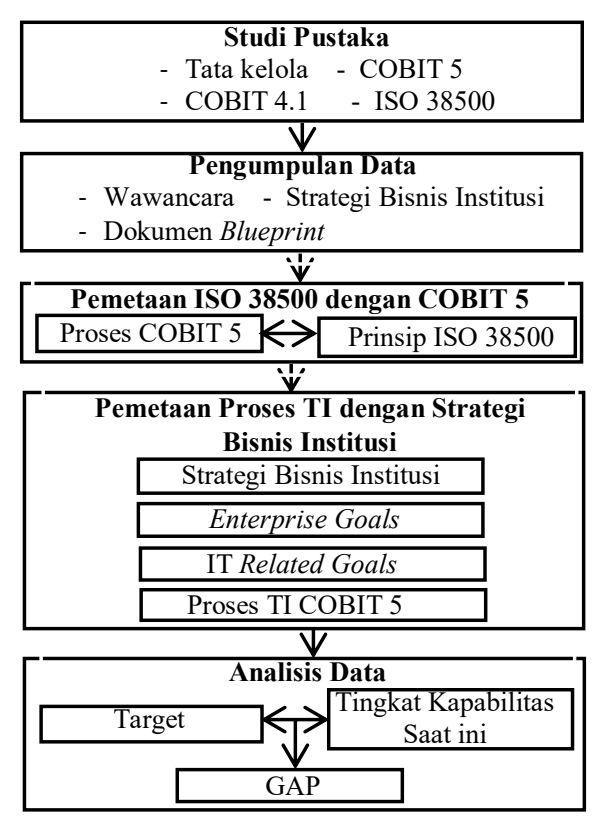

Gambar 3. Tahapan Penelitian

Berikut adalah penjelasan dari tahap penelitian :

a. Studi pustaka : melakukan pencarian referensi untuk penelitian ini.

b. Pengumpulan data : peneliti mengumpulkan data berupa blueprint, wawancara, strategi bisnis institusi.

c. Pemetaan COBIT 5 dengan ISO 38500 : merupakan pemetaan antara 37 domain COBIT dengan 6 prinsip ISO 38500.

d. Proses pemetaan berdasarkan strategi bisnis institusi : tahapan berikutnya yaitu melakukan pemetaan berdasarkan strategi bisnis antara lain pemetaan Enterprise Goals dengan visi misi 
institusi, IT Related Goals dengan visi misi institusi dan yang terakhir Domain COBIT 5 dengan IT Related Goals.

e. Analisis data : mengolah data yang telah diperoleh dari wawancara dan pengumpulan berkas lainya sehingga memperoleh tingkat kapabilitas dan GAP.

\section{HASIL DAN PEMBAHASAN}

Hasil wawancara pada penelitian ini diperoleh dari kepala UPT TIK di Universitas Semarang pada bulan Februari 2019. Dari hasil wawancara tersebut diperoleh data penelitian berupa visi dan misi institusi, data pendukung seperti blueprint serta data hasil kuisioner untuk dilakukan penilaian yang berkaitan dengan kesiapan sistem berdasarkan kriteria yang ditentukan. Setelah data diperoleh, selanjutnya dilakukan tahapan-tahapan pengukuran tingkat kapabilitas yang diproses menggunakan
COBIT 5 dan ISO 38500. Tahapan pengukuran tingkat kapabilitas adalah sebagai berikut:

1) Tahapan pertama yaitu dengan melakukan pemetaan antara Domain COBIT yang berjumlah 37 proses dan ISO 38500 berjumlah 6 prinsip sehingga memperoleh kesesuaian hasil 18 proses.

2) Tahapan kedua memetakan 7 poin visi misi institusi dengan 17 poin enterprise goals sehingga memperoleh 13 proses, sedangkan pemetaan 7 poin visi misi institusi dengan 17 poin IT Related Goals memperoleh 14 proses. Kemudian dipetakan kesesuaian antara hasil Enterprise Goals dengan IT Related Goals sehingga diperoleh 14 proses.

3) Tahapan selanjutnya memetakan 17 poin IT Related Goals dengan 37 proses Domain COBIT 5. Hasil pemetaan dapat dilihat pada Tabel 1.

Tabel 1. Pemetaan Domain COBIT 5 dengan IT Related Goals

\begin{tabular}{|c|c|c|c|c|c|c|}
\hline \multirow{2}{*}{ No } & \multirow{2}{*}{ ITRG } & \multicolumn{5}{|c|}{ Proses } \\
\hline & & EDM & APO & BAI & DSS & MEA \\
\hline 1 & 1 & 1,2 & $1,2,3,4,5,7,8$ & 1,2 & & \\
\hline 2 & 2 & & $1,12,13$ & 10 & 5 & 2 \\
\hline 3 & 3 & 1,5 & & & & \\
\hline 4 & 5 & 2 & $10,12,13$ & 1,6 & & \\
\hline 5 & 7 & $1,2,3$ & $2,8,9,10,11$ & $2,3,4,6$ & $1,2,3,4,6$ & 1 \\
\hline 6 & 8 & & 4 & 5,7 & & \\
\hline 7 & 9 & 4 & $1,3,4,10$ & 8 & & \\
\hline 8 & 11 & 4 & $1,3,4,7$ & $4,9,10$ & 1,3 & 1 \\
\hline 9 & 12 & & 8 & 2,7 & & \\
\hline 10 & 13 & & $5,7,11,12$ & 1,5 & & \\
\hline 11 & 14 & & 9,13 & 4,10 & 3,4 & \\
\hline 12 & 15 & 3 & 1 & & & 1,2 \\
\hline 13 & 16 & 4 & 1,7 & & & \\
\hline 14 & 17 & 2 & $1,2,4,7,8$ & 5,8 & & \\
\hline \multirow{2}{*}{$\begin{array}{l}\text { Domain } \\
\text { diperiksa }\end{array}$} & yang bisa & $1,2,3,4,5$ & $1,2,3,4,5,7,8,9,10,11,12$ & $1,2,3,4,5,6,7,8,9,10$ & $1,2,3,4,5,6$ & 1,2 \\
\hline & & $\begin{array}{c}5 \\
\text { proses }\end{array}$ & $\begin{array}{c}12 \\
\text { proses }\end{array}$ & $\begin{array}{c}10 \\
\text { proses }\end{array}$ & $\begin{array}{c}6 \\
\text { proses }\end{array}$ & $\begin{array}{c}2 \\
\text { proses }\end{array}$ \\
\hline
\end{tabular}

Pada Tabel 1 diperoleh hasil pemetaan pada domain EDM 5 proses, APO 12 proses, BAI 10 proses, DSS 6 proses dan MEA 2 proses. Tapan terakhir pemetaan yaitu pemetaan pada Tabel 1 yang menghasilkan Proses TI berdasarkan visi misi dengan hasil pemetaan COBIT dan ISO 38500, seperti yang ditampilkan pada Tabel 2.

Pada Tabel 2 Warna kuning menjelaskan proses yang memiliki kesesuain proses yang menghasilkan 17 proses dari pemetaan antara Proses TI berdasarkan visi misi dengan Proses TI berdasarkan COBIT 5 dan ISO 38500 antara lain EDM02, EDM05, APO02, APO03, APO4, APO05, APO07, APO08, APO09, APO11, APO12, BAI01, BAI02, BAI05, BAI08, MEA01, MEA02.

Setelah dilakukan pemetaan maka akan dilakukan perhitungan tingkat kapabilitas institusi.
Tingkat kapabilitas institusi merupakan hasil dari sebuah pemetaan. Hasil tingkat kapabilitas dan GAP bisa dilihat pada Tabel 3 .

Pada Tabel 3 menjelaskan tingkat kapabilitas dan GAP. Tingkat kapabilitas berada ditingkat 2 yang berarti managed process. Pada level ini institusi telah melakukan perencanaan, monitoring dan penyesuaian terhadap proses TI yang sedang berlangsung. Berdasarkan nilai target yang diharapkan perusahaan sebesar 3, maka terjadi GAP atau kesenjangan sebesar 1 yang berarti ada proses yang belum dijalankan sesuai dengan rencana. 
Tabel 2. Pemetaan Proses TI Berdasarkan Visi Misi dengan

\begin{tabular}{|c|c|c|c|}
\hline \multicolumn{4}{|c|}{ Proses ISO 38500} \\
\hline No & $\begin{array}{c}\text { Proses TI } \\
\text { berdasarkan visi } \\
\text { misi }\end{array}$ & $\begin{array}{c}\text { Proses TI } \\
\text { berdasarkan } \\
\text { ISO } 38500\end{array}$ & Keterangan \\
\hline 1 & EDM01 & EDM01 & \\
\hline 2 & EDM02 & EDM02 & EDM02 \\
\hline 3 & EDM03 & EDM03 & \\
\hline 4 & EDM04 & EDM04 & \\
\hline 5 & EDM05 & EDM05 & EDM05 \\
\hline 6 & APO01 & APO01 & \\
\hline 7 & APO02 & APO02 & APO02 \\
\hline 8 & APO03 & APO03 & APO03 \\
\hline 9 & APO04 & APO04 & APO04 \\
\hline 10 & APO05 & APO05 & APO05 \\
\hline 11 & APO06 & APO06 & \\
\hline 12 & APO07 & APO07 & APO07 \\
\hline 13 & APO08 & APO08 & APO08 \\
\hline 14 & APO09 & APO09 & APO09 \\
\hline 15 & APO10 & APO10 & \\
\hline 16 & APO11 & APO11 & APO11 \\
\hline 17 & APO12 & APO12 & APO12 \\
\hline 18 & APO13 & APO13 & \\
\hline 19 & BAI01 & BAI01 & BAI01 \\
\hline 20 & BAI02 & BAI02 & BAI02 \\
\hline 21 & BAI03 & BAI03 & \\
\hline 22 & BAI04 & BAI04 & \\
\hline 23 & BAI05 & BAI05 & BAI05 \\
\hline 24 & BAI06 & BAI06 & \\
\hline 25 & BAI07 & BAI07 & \\
\hline 26 & BAI08 & BAI08 & BAI08 \\
\hline 27 & BAI09 & BAI09 & \\
\hline 28 & BAI10 & BAI10 & \\
\hline 29 & DSS01 & DSS01 & \\
\hline 30 & DSS02 & DSS02 & \\
\hline 31 & DSS03 & DSS03 & \\
\hline 32 & DSS04 & DSS04 & \\
\hline 33 & DSS05 & DSS05 & \\
\hline 34 & DSS06 & DSS06 & \\
\hline 35 & MEA01 & MEA01 & MEA01 \\
\hline 36 & MEA02 & MEA02 & MEA02 \\
\hline 37 & MEA03 & MEA03 & \\
\hline
\end{tabular}

\begin{tabular}{cccc}
\multicolumn{4}{c}{ Tabel 3. Pencapaian Tingkat Kapabilitas dan $G A P$} \\
\hline ID Proses & Target & $\begin{array}{c}\text { Capability } \\
\text { Level }\end{array}$ & GAP \\
\hline EDM02 & 3 & 2 & 1 \\
EDM05 & 3 & 2 & 1 \\
APO02 & 3 & 2 & 1 \\
APO03 & 3 & 2 & 1 \\
APO04 & 3 & 2 & 1 \\
APO05 & 3 & 2 & 1 \\
APO07 & 3 & 2 & 1 \\
APO08 & 3 & 2 & 1 \\
APO09 & 3 & 2 & 1 \\
APO11 & 3 & 2 & 1 \\
APO12 & 3 & 2 & 1 \\
BAI01 & 3 & 2 & 1 \\
BAI02 & 3 & 2 & 1 \\
BAI05 & 3 & 2 & 1 \\
BAI08 & 3 & 2 & 1 \\
MEA01 & 3 & 2 & 1 \\
MEA02 & 3 & 2 & 1 \\
\hline
\end{tabular}

\section{KESIMPULAN}

Dalam melakukan analisis pencapaian target capability level dilakukan dengan cara diskusi dan wawancara langsung dengan Kepala UPT TIK Universitas Negeri Semarang. Pengukuran tingkat kapabilitas sistem tata kelola TI menggunakan COBIT 5 dengan ISO 38500 telah berhasil dilakukan dan memperoleh 17 Domain COBIT dengan pengukuran berada pada tingkat kapabilitas 2 . Hal ini berarti pada tingkat managed process, institusi telah melakukan perencanaan, pengontrolan dan penyesuaian terhadap proses TI yang sedang berlangsung. Penelitian ini menghasilkan nilai GAP sebesar 1 diperoleh dari selisih antara target denan tingkat kapabilitas. Dengan ini dapat dikatakan bahwa kombinasi COBIT 5 dan ISO 38500 dapat dijadikan acuan dalam memperbaiki sistem tata kelola TI. Pada penelitian berikutnya diharapkan proses Teknologi Informasi dapat meningkatkan indikator lainya dengan strategi bisnis institusi.

\section{DAFTAR PUSTAKA}

AHUJA, S. DAN CHAN, Y. E. 2015., IT Security Governance: A Framework based on ISO 38500. CONF-IRM 2015 Proceedings, 27.

ANDRY, J. F., 2016. Audit of IT Governance Based on COBIT 5 Assessments: A Case Study. Jurnal Nasional Teknologi Dan Sistem Informasi, 2(2), 27-34.

FRANSISKUS ADIKARA., 2013. Implementasi Tata Kelola Teknologi Informasi Perguruan Tinggi Berdasarkan Cobit 5 Pada Laboratorium Rekayasa Perangkat Lunak Universitas Esa Unggul. Seminar Nasional Sistem Informasi Indonesia, 2-4.

GREMBERGEN, W.V. DAN HAES, S.D., 2009. Enterprise Governance of Information Tecnology, USA:Springer.

ISACA., 2016. COBIT 5 A Business Framework for the Governance and Management of Enterprise IT- Executive Summary. In Isaca.Org.

ISACA., 2013. COBIT $®$ Process Assessment Model (PAM): Using COBIT $® 5$.

ISACA., 2012. COBIT 5 A Bussiness framework for the Governance and Management of Enterprise IT, USA:ISACA.

JUIZ, C., GUERRERO, C. DAN LERA, I., 2014. Implementing Good Governance Principles for the Public Sector in Information Technology Governance Frameworks.

JUIZ, C., GOMEZ, M. \& BARCELO, M, I., 2012, Business/IT Projects Alignment through the Project Portofolio Approval Process as IT Governance Instrument, Proceedings of Social and Behavioral Sciences, 65 (2012) 70-75.

MASKUR, M., ADOLONG, N. \& MOKODONGAN, R., 2018. Implementasi Tata Kelola Teknologi Informasi Menggunakan Framework Cobit 5 Di Bpmptsp Bone Bolango. Masyarakat Telematika Dan Informasi : Jurnal Penelitian Teknologi Informasi Dan Komunikasi, 8(2), 109.

MUTHOHAROH, I., DWIPA, E. F. \& DEWI, R. S., 
2019. Analisis Tingkat Kematangan Pendistribusian Ruang Kelas Maturity Level Measurement Classroom Distribution Using COBIT. 1(1).

NUGROHO, H., 2017. Proposed IT Governance at Hospital Based on COBIT 5 Framework. IJAIT (International Journal of Applied Information Technology), 1(02), 52-58.

PASQUINI, A., 2013, COBIT 5 and the Process Capability Model. Improvements Provided for IT Governance Process, Procedings of FIKUSZ '13 Symposium for young researches, 67-76

PUTRI, R. E. DAN SURENDRO, K., 2016. A process capability assessment model of IT governance based on ISO 38500. 2015 International Conference on Information Technology Systems and Innovation, ICITSI 2015 - Proceedings, 0-5.

ROOSWATI, R., DAN LEGOWO, N., 2018. Evaluation of IT Project Management Governance Using Cobit 5 Framework in Financing Company. Proceedings of 2018 International Conference on Information Management and Technology, ICIMTech 2018, (September), 81-85.

SARNO, R., 2009. Strategi Sukses Bisnis dengan Teknologi Informasi (Berbasis Balanched Scorecard dan COBIT), ITS Press : Surabaya. 
Halaman ini sengaja dikosongkan 